\title{
Avaliação in vitro da atividade antimicrobiana de antissépticos bucais
}

\author{
Ana Cristina Azevedo Moreira ${ }^{1}$ \\ Marlus Henrique Queiroz Pereira \\ Mariana Ribeiro Porto ${ }^{3}$ \\ Leandro Antônio Palmeira da Rocha ${ }^{3}$ \\ Bruno Campos Nascimento ${ }^{3}$ \\ Péricles Maia Andrade
}

\begin{abstract}
Resumo
O objetivo deste trabalho foi avaliar a atividade antimicrobiana de antissépticos bucais sobre Streptococcus mutans ATCC 25175, Pseudomonas aeruginosa ATCC 115442, Enterococcus faecalis, Staphylococcus aureus ATCC 6538 e sobre bactérias obtidas de uma amostra de saliva de 10 indivíduos. Foram analisados enxaguatórios com os seguintes antissépticos: gluconato de clorexidina a $0,12 \%$; gluconato de clorexidina a $0,2 \%$; cloreto de cetilpiridínio com e sem flúor; timol; triclosan com flúor ; extrato de malva com flúor e xilitol e peróxido de hidrogênio. A técnica utilizada foi por difusão em ágar, método da placa com orifício, com incubação a $37^{\circ} \mathrm{C}$ em aerobiose e microaerofilia. Após incubação, observou-se a presença ou a ausência de halo de inibição de crescimento em torno dos orifícios. A formação de halo demonstrou atividade antimicrobiana. Nos enxaguatórios com timol e com flúor associado ao xilitol, não foi evidenciada atividade sobre as bactérias utilizadas. Os outros enxaguatórios apresentaram eficácia sobre as bactérias, com exceção dos que continham cloreto de cetilpiridínio, que não apresentaram atividade sobre Pseudomonas aeruginosa, e do enxaguatório com malva associada ao flúor exilitol, sem atividade sobre P. aeruginosa, $S$. mutans e bactérias da saliva. Os enxaguatórios com triclosan com flúor, peróxido de hidrogênio e clorexidina foram os mais efetivos, de acordo com o diâmetro dos halos de inibição formados e a metodologia utilizada. Os resultados obtidos comprovaram que substâncias antissépticas podem constituir-se em opção complementar para o controle do biofilme dental e de infecçôes bucais, somando-se aos métodos já preconizados e de efeitos comprovados.
\end{abstract}

Palavras-chave: Antissépticos bucais - Atividade antimicrobiana - Biofilme dental - Difusão em ágar.

\section{INTRODUÇÃO}

A saúde bucal depende da utilização de medidas de caráter curativo e preventivo. A cárie dentária e a doença periodontal são doenças relacionadas com a presença do biofilme dental
(MONFRIM; RIBEIRO, 2000; GEBRAN; GEBERT, 2002), que pode ser definido como uma comunidade microbiana embebida por uma matriz aglutinante, firmemente aderida a uma superfície sólida e úmida (LORENZO, 2004). Para o controle do biofilme dental e das

\footnotetext{
${ }^{1}$ Professora da Universidade Federal da Bahia - Laboratório de Microbiologia Oral.

2 Acadêmico da Faculdade de Nutrição da Universidade Federal da Bahia.

${ }^{3}$ Acadêmicos da Faculdade de Odontologia da Universidade Federal da Bahia.

${ }^{4}$ Acadêmico da Faculdade de Medicina Veterinária da Universidade Federal da Bahia.

Correspondência para / Correspondence to:

Ana Cristina Azevedo Moreira

Rua da Paz 257, apto. 201 - Graça.

40150-140 Salvador - Bahia - Brasil.

E-mail: crisazev@ufba.br
} 
patologias decorrentes da sua presença, diversos métodos são propostos: os recursos mecânicos e químicos, ou através do controle da dieta. $\mathrm{O}$ controle mecânico representa o método mais valioso utilizado na prevenção e remoção do biofilme e consiste na escovação e no uso do fio dental. Porém nem sempre é realizado adequadamente. Desse modo, diversas substâncias têm sido utilizadas para o controle químico da placa bacteriana, como adjutórias aos procedimentos mecânicos (MONFRIN; RIBEIRO, 2000; GEBRAN; GEBERT, 2002; ADDY, 2005).

O uso de substâncias químicas antissépticas para a redução ou eliminação do biofilme dental é recomendado para pacientes com dificuldades operacionais frente ao controle mecânico. Elas estão incorporadas em dentifrícios ou em soluções para bochechos, os enxaguatórios ou colutórios (MONFRIN; RIBEIRO, 2000; GEBRAN;GEBERT, 2002).

Os enxaguatórios representam o meio mais simples para a veiculação de substâncias antissépticas, sendo uma mistura do componente ativo, água, álcool, surfactantes, umectantes e flavorizantes (TORRES et al., 2000).

As propriedades de um antisséptico ideal incluem: estabilidade, baixa tensão superficial, poder germicida e letal em baixas concentraçôes, ausência de toxicidade e poder de penetração. No entanto, nenhum produto disponível no mercado possui todos os requisitos acima citados, o que justifica os efeitos colaterais ou a pouca eficiência apresentada por alguns (MONFRIN; RIBEIRO, 2000).

Várias substâncias antimicrobianas são utilizadas sob a forma de enxaguatórios: fluoreto de sódio, cloreto de cetilpiridínio, triclosan, timol, clorexidina, tirotricina, dentre outras (MONFRIN; RIBEIRO, 2000).

Os benefícios na prevenção à cárie por sais de fluoreto estão bem estabelecidos. Além da atividade durante a mineralização, o íon fluoreto contribui para efeitos cariostáticos, porque influencia na ecologia do biofilme dental. Em odontologia, é empregado sob diversas formas. Nos enxaguatórios, o fluoreto de sódio pode ser utilizado a $0,05 \%$ em bochechos diários (TORRES et al., 2000; ADDY, 2005).
O cloreto de cetilpiridínio, presente nas marcas comerciais Cepacol e Oral B, é um composto monovalente, catiônico, tensoativo e pertence ao grupo dos compostos quaternários de amônia (MENDES et al., 1995). É mais efetivo contra Gram-positivos, provocando aumento da permeabilidade celular e rompimento da parede celular bacteriana (GEBRAN; GEBERT, 2002). O uso prolongado dessa substância pode causar sensação de queimação, descoloração dos dentes, ulcerações recorrentes e aumento da formação do cálculo (GRANJEIRO et al., 1993).

A clorexidina é uma bisguanida catiônica, disponível principalmente na forma de sais de digluconato. Apresenta amplo espectro sobre as bactérias Gram-positivas, Gram-negativas, fungos e leveduras. Diminui significativamente a placa, pois afeta a aderência microbiana, aumenta a permeabilidade celular por meio do rompimento da bactéria ou age através da coagulação e precipitação dos seus constituintes citoplasmáticos. Pode ser utilizada em concentrações de $0,12 \%, 0,2 \%$ e $2 \%$, sendo a clorexidina a $0,12 \%$ a mais indicada, devido à associação da eficácia contra os microrganismos e a diminuição dos efeitos adversos, quando comparada com soluçôes mais concentradas (MENDES et al., 1995; GEBRAN; GEBERT, 2002; SOUZA; ABREU, 2003).

O triclosan é um fenol sintético, não iônico, de baixa toxicidade, e não provoca desequilíbrio na cavidade bucal (SABA-CHUJFI et al., 1998; GEBRAN; GEBERT, 2002). Tem amplo espectro bacteriano, sendo eficaz contra Gram-positivos e Gram-negativos, demonstrando efetividade também contra Mycobacterium e principalmente bactérias anaeróbias, assim como esporos e fungos da espécie Candida. Sua ação ocorre pela lise da membrana citoplasmática do microorganismo (SABA-CHUJFI et al., 1998; MONFRIN; RIBEIRO, 2000). O triclosan pode ser encontrado associado ao copolímero gantrez 0,2\% (metoxietileno mais ácido maléico). Essa associação é realizada para aumentar a sua presença na cavidade bucal, devido à baixa substantividade apresentada pelo antisséptico. O copolímero também aumenta o seu espectro 
de ação sobre bactérias Gram negativas e leveduras (SABA-CHUJFI et al., 1998; GEBRAN; GEBERT, 2002; Bugno et al., 2006).

A tirotricina (gramicidina 20 a $25 \%$ e tirocidina cerca de 60\%), presente no enxaguatório Malvatricin, é oriunda do Bacillus brevis. A depender da concentração, pode ter ação bacteriostática ou bactericida. Atua sobre bactérias Gram-negativas e tem ação tópica duradoura (MONFRIN; RIBEIRO, 2000). O enxaguatório também apresenta extrato de malva além de outros componentes em sua composição, existindo formulações sem tirotricina.

O enxaguatório comercialmente denominado Listerine está na categoria dos óleos essenciais, sendo composto por timol, eucaliptol, mentol e salicilato de metila. Age lesando a parede celular bacteriana, inibindo os sistemas enzimáticos e diminuindo os lipopolissacarídeos e o conteúdo protéico da placa bacteriana. Possui baixa substantividade. Sensação de queimação, gosto amargo, manchas nos dentes e injúrias ao tecido bucal constituem seus efeitos colaterais (MENDES et al., 1995). O peróxido de hidrogênio, presente no enxaguatório Peroxil, é um agente oxidante, que atua sobre a membrana lipídica e no DNA, sendo ativo contra micro-organismos anaeróbios. Apresenta como efeitos colaterais o desequilíbrio da microbiota oral, queimaduras e irritação dos tecidos bucais (Torres et al., 2000; GEBRAN; GEBERT, 2002).

No Brasil, os enxaguatórios bucais são classificados como produtos de higiene pessoal e cosméticos. As formulações que apresentam indicações específicas como antissépticos, antiplaca e de uso infantil são classificadas como produtos de grau 2 e demandam a comprovação da sua segurança e eficácia antimicrobiana (AGÊNCIA NACIONAL DE VIGILÂNCIA SANITÁRIA, 2005).

A avaliação da eficácia antimicrobiana dos antissépticos bucais pode ser realizada por testes in vivo ou in vitro. Os últimos geralmente são adaptaçôes dos procedimentos de difusão em ágar, da determinação da concentração inibitória mínima (CIM) ou de ensaios para a determinação do tempo de redução decimal (BOTELHO, 2000), não havendo, no Brasil, uma metodologia oficial para a avaliação da atividade antimicrobiana dos enxaguatórios bucais (BUGNO et al., 2006).

O objetivo deste estudo é avaliar in vitro a atividade antimicrobiana de antissépticos bucais comercialmente disponíveis sobre Streptococcus mutans ATCC 25175, Pseudomonas aeruginosa ATCC 115442, Staphylococcus aureus ATCC 6538, Enterococcus faecalis e bactérias mesófilas facultativas obtidas de saliva.

\section{MATERIAIS E MÉTODOS}

O material deste estudo foi constituído de antissépticos bucais comercialmente disponíveis em farmácias, drogarias e supermercados da cidade de Salvador, Bahia. A identificação dos produtos foi realizada segundo o seu principio ativo e sua marca comercial. Foram analisados nove enxaguatórios bucais com os antissépticos descritos no Quadro 1. Todos os produtos foram avaliados quanto à sua atividade antimicrobiana sem diluição, conforme a indicação de uso. Para a realização das análises, a técnica utilizada foi por difusão em ágar, método da placa com orifício, de acordo com o procedimento operacional $n^{\circ} 65.3210 .006$ do Instituto Nacional de Controle de Qualidade em Saúde (2006).

Os antissépticos foram testados com culturas de Streptococcus mutans ATCC25175, Pseudomonas aeruginosa ATCC115442, Staphylococcus aureus ATCC- 6538, Enterococcus faecalis e um pool de saliva coletada em 10 indivíduos. As culturas foram ativadas em tubos com $10 \mathrm{~mL}$ de caldo BHI (Brain Heart Infusion, Difco) e repicadas por 3 dias consecutivos, com incubação a $35^{\circ} \mathrm{C}$, verificando-se sempre a sua pureza através da técnica de Gram.

Após o terceiro repique, adicionou-se com um pipetador automático $0,2 \mathrm{ml}$ da cultura bacteriana a $30 \mathrm{ml}$ de ágar BHI fundido e resfriado, homogeneizando e vertendo o conteúdo em placa de Petri, fazendo dois orifícios através de cilindros metálicos estéreis com $1,5 \mathrm{~cm}$ de diâmetro e $1 \mathrm{~cm}$ de altura, 
deixando solidificar. Após a solidificação, foi colocado, nos orifícios, o antisséptico em teste. Para cada antisséptico, foram feitas placas em duplicatas, com um total de quatro orifícios. Foram feitos dois controles. O controle positivo com triclosan $0,5 \%$ em álcool, e o controle negativo com soro fisiológico $(\mathrm{NaCl} 0,85 \% \mathrm{em}$ água destilada). $\mathrm{O}$ mesmo procedimento técnico utilizado para os testes foi adotado para os controles.

As placas foram incubadas em estufa bacteriológica regulada a $37^{\circ} \mathrm{C}$ por 24 horas. A leitura foi feita observando-se a formação de halos de inibição de crescimento que, quando presentes, indicavam propriedades bacteriostáticas ou bactericidas dos enxaguatórios. Os resultados obtidos foram expressos através da média do diâmetro dos halos de inibição de crescimento formados em volta dos orifícios (Quadro 1).

\section{RESULTADOS}

Os resultados obtidos nas análises microbiológicas realizadas em nove enxaguatórios bucais frente às bactérias utilizadas estão descritos nas Figuras 1 a 12. Nas Figuras 1, 2 e 3, são visualizados o aspecto do crescimento das bactérias nas placas, os halos de inibição de crescimento produzidos e os controles positivo e negativo. Nas Figuras $4 \mathrm{a}$ 12 , estão representados os gráficos com as médias dos halos de inibição do crescimento das bactérias frente aos antissépticos sob teste.

Avaliando-se a atividade dos princípios ativos componentes dos enxaguatórios sobre cada bactéria, exibiram atividade contra $S$. mutans os enxaguatórios com peróxido de hidrogênio (Peroxil), clorexidina a 0,12 e a $0,2 \%$ (Periogard e Paradontax), cloreto de cetilpiridínio (Cepacol e Oral B) e triclosan com flúor (Plax). A maioria dos antissépticos foi eficaz para $S$. aureus, com exceção dos enxaguatórios com flúor + xilitol (Fluormint) e timol (Listerine). Para Enterococcus faecalis, foram ativos clorexidina (Periogard e Paradontax), extrato de malva, fluoreto e xilitol (Malvatricin), peróxido de hidrogênio (Peroxil), cloreto de cetilpiridinio (Cepacol e Oral B) e triclosan (Plax). Para P. aeruginosa, foram eficazes os enxaguatórios com triclosan, clorexidina e peróxido de hidrogênio. Foram ativos sobre as bactérias da saliva os enxaguatórios com cloreto de cetilpiridínio, triclosan, clorexidina e peróxido de hidrogênio.

\section{DISCUSSÃO}

A produção de estudos sobre a eficácia de medicamentos, particularmente os antissépticos, é pouco expressiva e pouco divulgada. Consequentemente, os profissionais de saúde têm uma visão sobre eles veiculada pelos fabricantes, sendo de vital importância a realização de testes in vitro para confirmar a sua efetividade, possibilitando melhor escolha do produto a ser prescrito.

Cloreto de cetilpiridínio é um antisséptico muito utilizado em bochechos, devido às suas propriedades antimicrobianas. Os resultados obtidos com o cloreto de cetilpiridínio, princípio ativo dos enxaguatórios Cepacol e Oral B (Figura 4; Figura 5), demonstraram a sua efetividade para $S$. mutans, E. faecalis, $S$. aureus e bactérias da saliva, confirmando o seu principal alvo de ação, sobre bactérias Gram positivas, e a ausência de atividade contra $P$. aeruginosa, bactéria Gram negativa. $O$ resultado obtido com o Streptococcus mutans, no qual foi evidenciada atividade do cloreto de cetilpiridínio sobre esse microrganismo, foi semelhante ao de Tirapelli e Ito (2003) que, testando a atividade de antissépticos sobre amostras de saliva, obtiveram, após o uso do cloreto de cetilpiridínio, a inibição do crescimento de estreptococos do grupo mutans. Pitten e Kramer (2001) verificaram que os produtos à base de cloreto de cetilpiridínio reduziram as contagens microbianas na saliva entre 2 e 2,5 ciclos logarítmicos. Mota e colaboradores (2004), estudando in vivo a eficácia de dois enxaguatórios bucais no controle da placa supra-gengival, concluíram que o cloreto de cetilpiridínio foi eficaz na prevenção da formação da placa.

Óleos essenciais, como timol, mentol e eucaliptol, constituem os princípios ativos do 
Quadro 1. Antissépticos testados, marca e fabricante.

\begin{tabular}{|lll|}
\hline Antissépticos & Marca & Fabricante \\
\hline Cloreto de Cetilpiridínio & Cepacol & Aventis Pharma \\
Triclosan + Fluoreto de Sódio & Plax & Colgate \\
Fluoreto de sódio+Cloreto de cetilpiridinio & Oral-B & Lab. Rety \\
Fluoreto de sódio + Xilitol + Timol & Fluor mint & Daudt \\
Extrato de Malva +Fluoreto de sódio + xilitol & Malvatricin & Daudt \\
Peróxido de Hidrogênio & Peroxil & Colgate \\
Timol & Listerine & Pfizer \\
Clorexidina $0,12 \%$ & Periogard & Colgate \\
Clorexidina $0,2 \%$ & Paradontax & SmithKline B.C.H. \\
\hline
\end{tabular}

Figura 1. Halo de inibição de crescimento de $S$. mutans utilizando Peróxido de hidrogênio.

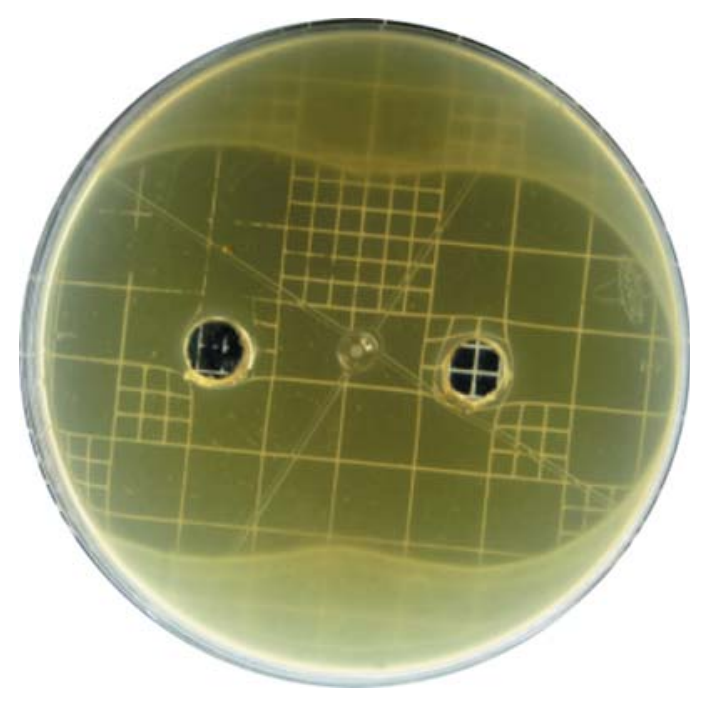

Figura 2. Halo de inibição de crescimento de $E$. faecalis utilizando Clorexidina a $0,12 \%$ (Periogard).

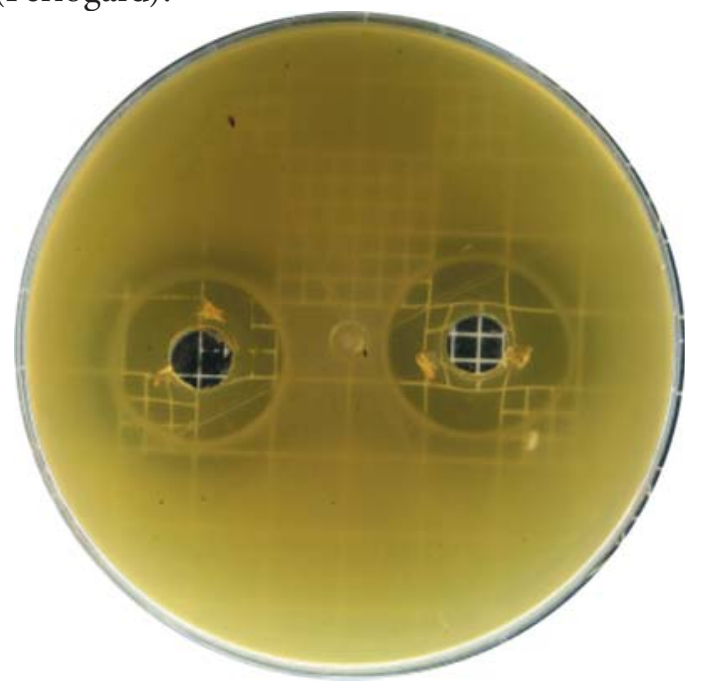

Figura 3. Controle negativo (esquerda) e positivo (direita)
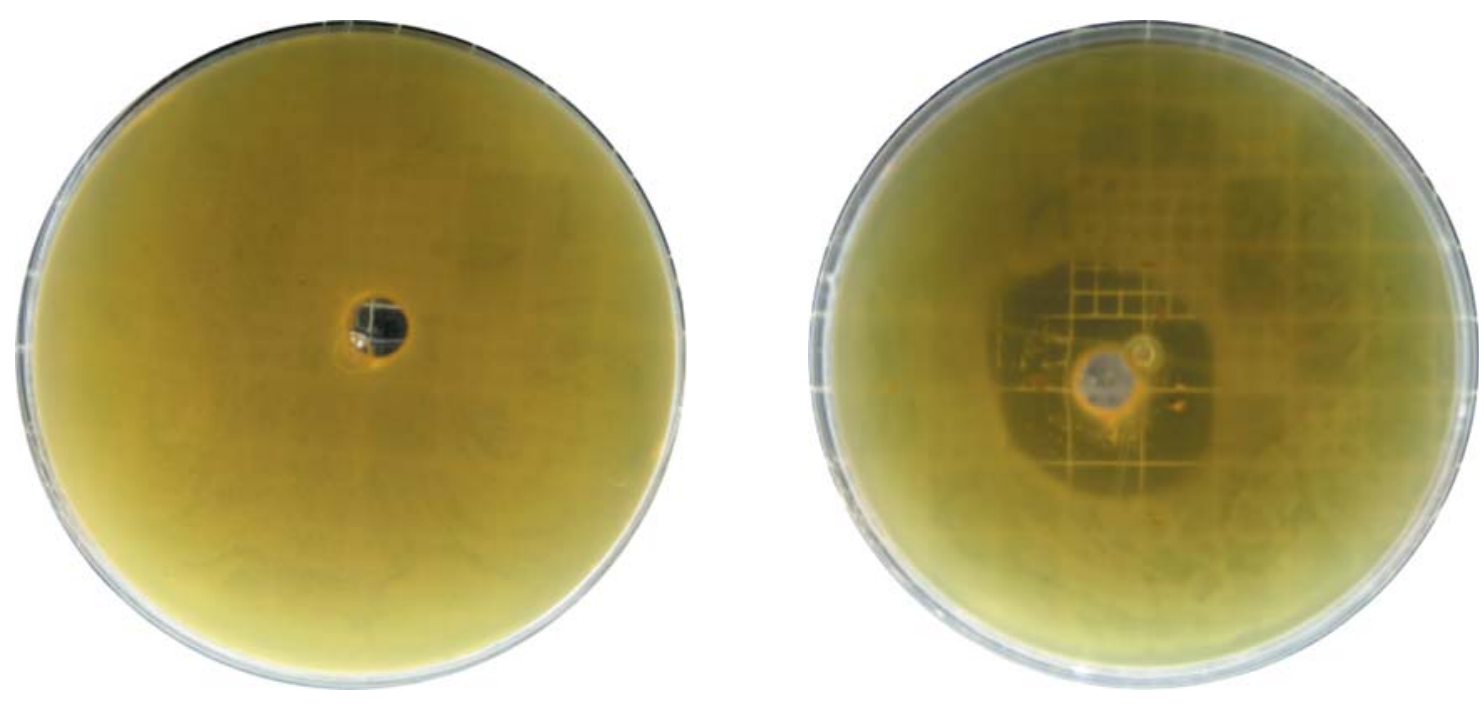
Figura 4. Cloreto de Cetilpiridínio.

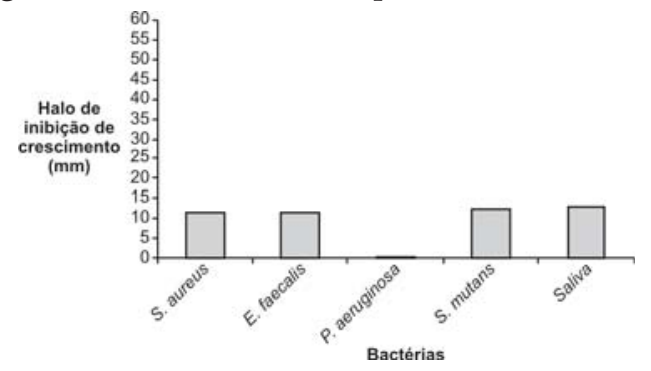

Figura 5. Cloreto de Cetilpiridinio +Fluoreto de Sódio (Oral B).

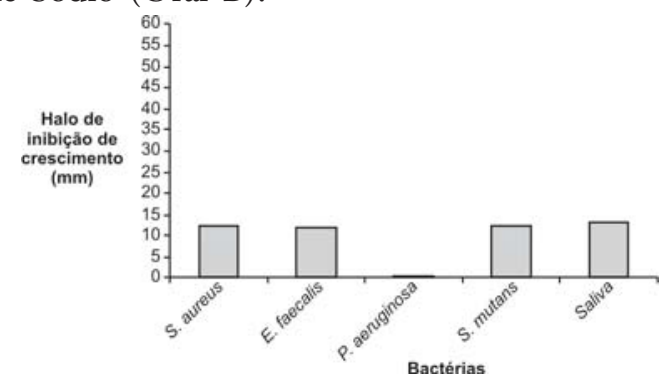

Figura 6. Triclosan (Plax).

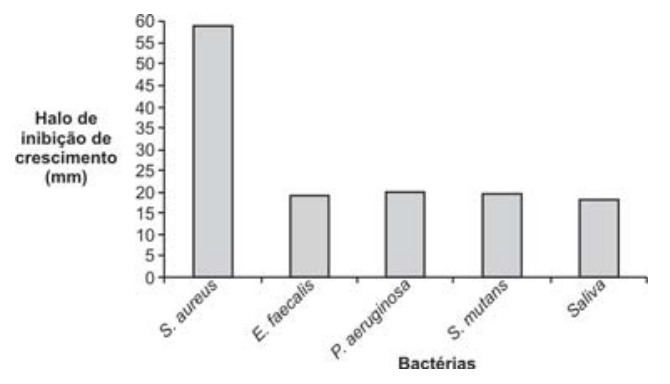

Figura 7. Fluoreto de Sódio+Xilitol + Timol (Fluomint).

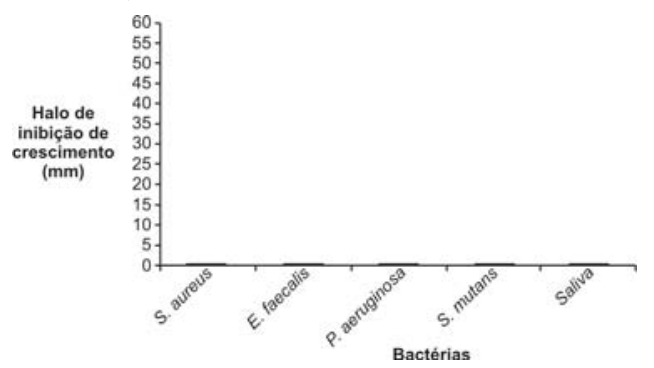

Figura 8. Extrato de Malva + Flúor + Xilitol (Malvatricin).

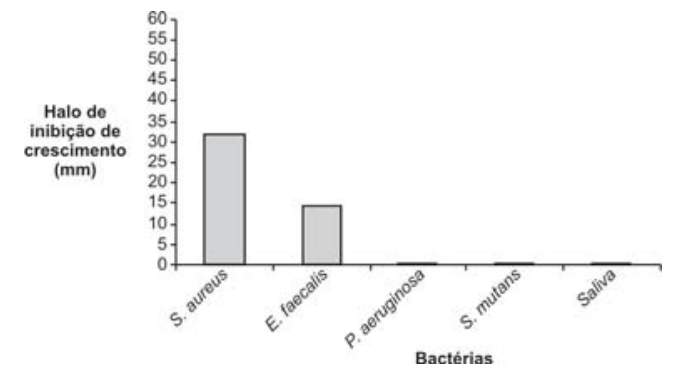

Figura 9. Peróxido de Hidrogênio (Peroxil).

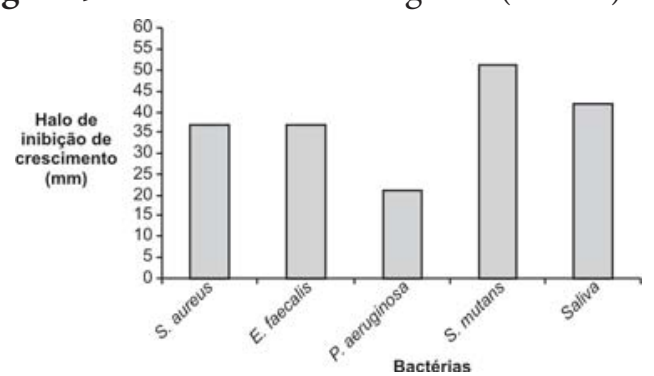

Figura 10. Timol (Listerine).

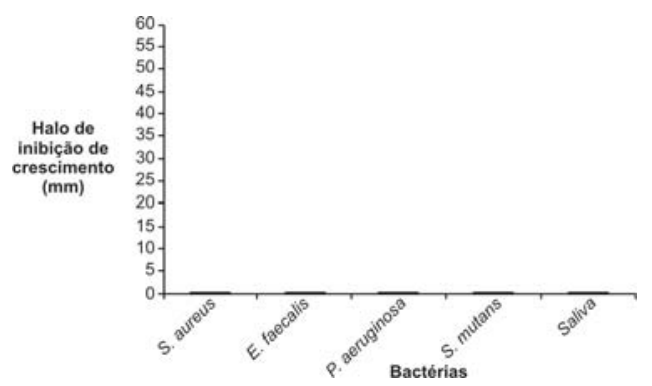

Figura 11. Clorexidina 0,12\% (Periogard).

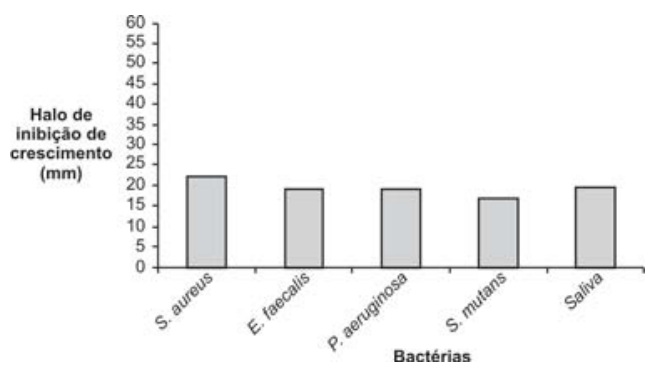

Figura 12. Clorexidina 0,2\% (Parodontax).

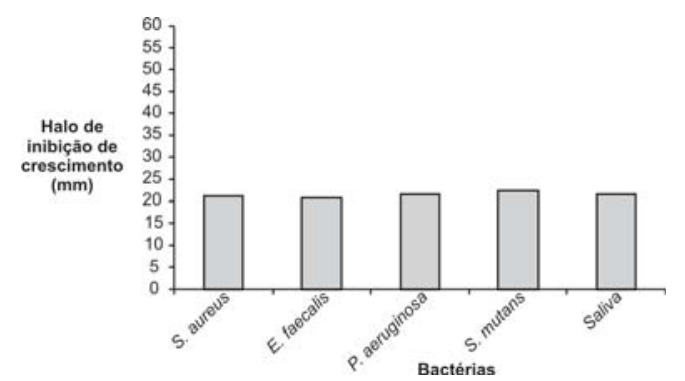

Listerine. São compostos fenólicos que agem contra as bactérias rompendo a parede celular ou inibindo a ação enzimática. São aceitos pela ADA (American Dental Association) para o controle da placa bacteriana e gengivite (MENDES et al., 1995; GEBRAN; GEBERT, 2002).

Os resultados visualizados na Figura 10 expressam a ausência de atividade antibacteriana apresentada pelo Listerine. Como a técnica 
utilizada neste estudo foi por difusão em Agar, e o fenômeno da difusão depende das propriedades físico-químicas do produto e do meio de cultura, a ausência da formação de halos de inibição de crescimento poderia estar associada ao grau de difusão do antisséptico listerine em ágar, não estando obrigatoriamente relacionada com a ausência de atividade antimicrobiana. Monfrin e Ribeiro (2000) evidenciaram pouca eficácia do Listerine na redução da microbiota da saliva. No entanto, utilizando o método de regressão linear para avaliar a eficácia antimicrobiana de enxaguatórios bucais, Bugno e colaboradores (2006) evidenciaram que o produto à base de óleos essenciais (timol) foi o que apresentou melhor atividade antimicrobiana, em relação aos demais.

Os resultados obtidos com o enxaguatório Fluormint, cujos princípios ativos são fluoreto de sódio associado ao xilitol e timol (Figura 7), foram idênticos aos obtidos com o Listerine (timol), não tendo o produto demonstrado atividade antimicrobiana. Esses resultados podem estar relacionados com a capacidade de difusão do flúor em ágar. Monfrin e Ribeiro (2000), testando antissépticos com flúor, relataram resultados concordantes com os ora obtidos. Esses autores comentaram que o mecanismo anticariogênico do flúor deve ser exercido nos ciclos de desmineralização e remineralização, estando o antisséptico mais apropriado à deposição de flúor do que à redução de micro-organismos.

Os testes realizados com o Malvatricin, cujos princípios ativos são malva, fluoreto de sódio e xilitol, demonstraram efetividade do enxaguatório sobre $E$. faecalis e $S$. aureus. Utilizando meio de cultura líquido, Monfrin e Ribeiro (2000) obtiveram com o mesmo enxaguatório, porém com adição de tirotricina, redução dos microrganismos da saliva, embora não aconselhassem a sua utilização indiscriminadamente, devido à presença de substância antibiótica em sua fórmula.

O peróxido de hidrogênio é um agente oxidante usado em endodontia para desinfecção de canais radiculares e, em periodontia, por tempo determinado, pois o seu uso poderá causar desequilíbrio da microbiota oral. Apresenta como efeitos colaterais queimaduras e irritação dos tecidos bucais (GEBRAN; GEBERT, 2002). Os resultados expressos na Figura 9 demonstraram elevada efetividade do peróxido de hidrogênio (Peroxil) sobre todas as bactérias utilizadas nesta investigação, especialmente sobre $S$. mutans. Apesar de sua eficiência, esse produto deverá ser utilizado para fins específicos, devido aos efeitos colaterais acima mencionados.

Triclosan é um derivado fenólico utilizado em soluções para bochechos e apresenta amplo espectro de ação sobre os microrganismos. Os resultados visualizados na Figura 6 demonstraram a atividade do triclosan sobre todas as bactérias utilizadas (Gram positivas e Gram negativas). Nesse antisséptico, peróxido de hidrogênio e gluconato de clorexidina foram os princípios ativos que demonstraram maior atividade e espectro de ação, de acordo com o diâmetro dos halos de inibição de crescimento produzidos.

Avaliando a eficácia antimicrobiana de anti-sépticos bucais, Tirapelli e Ito (2003) constataram que o enxaguatório com triclosan foi o mais efetivo sobre estreptococos do grupo mutans. Porém Monfrin e Ribeiro (2000), testando o mesmo antisséptico, obtiveram pouca redução dos microrganismos da saliva.

As Figuras 11 e 12 representam os resultados obtidos com enxaguatórios que contêm clorexidina em concentraçôes de 0,12 e $0,2 \%$ (Periogard e Paradontax, respectivamente). Os enxaguatórios foram ativos contra todas as bactérias sob teste, incluindo Pseudomonas aeruginosa. Não houve diferença significante nas médias do diâmetro dos halos de inibição do crescimento entre os dois enxaguatórios, nas diluiçōes de $0,12 \%$ e $0,2 \%$. Esses resultados foram concordantes com os descritos por Monfrin e Ribeiro (2000), que obtiveram, com o enxaguatório que continha clorexidina, o melhor resultado na redução dos microrganismos da saliva.

\section{CONCLUSÃO}

De acordo com a metodologia utilizada neste estudo, pode-se concluir que foram eficazes 
sobre Streptococcus mutans, Staphylococcus aureus, Enterococcus faecalis, Pseudomonas aeruginosa e bactérias mesófilas facultativas da saliva os enxaguatórios com peróxido de hidrogênio (Peroxil), triclosam com flúor (Plax), clorexidina a $0,12 \%$ (Periogard), a 2\% (Paradontax). Exibiram diferenças quanto ao espectro de ação sobre as bactérias o cloreto de cetilpiridínio (Oral B e Cepacol) e malva, flúor e xilitol (Malvatricin).

Os enxaguatórios com timol (Listerine) e associação de fluoreto de sódio, xilitol e timol (Fluormint) não demonstraram atividade antibacteriana. Como esses são antissépticos bastante utilizados, recomenda-se a realização de novos ensaios utilizando-se outra metodologia.
Os resultados comprovaram que os antissépticos bucais podem constituir-se em opção complementar para o controle do biofilme dental e de infecçôes como a cárie e a doença periodontal, embora o uso indiscriminado dessas substâncias possa causar desequilíbrio ecológico, estimulando a multiplicação de microrganismos resistentes. Consequentemente, devem ser utilizados com critérios ou quando os métodos profiláticos convencionais não se mostrarem efetivos.

Como o Brasil não dispõe de uma metodologia oficial para a avaliação da atividade antimicrobiana dos antissépticos bucais, evidencia-se a necessidade de elaboração de normas técnicas para a realização do controle de qualidade desses produtos.

\title{
Evaluation in vitro of the antimicrobial activity of buccal antiseptics
}

\begin{abstract}
This work aims at evaluating the antimicrobial activity of buccal antiseptics on Streptococcus mutans ATCC 25175, Pseudomonas aeruginosa ATCC 115442, Enterococcus faecalis, Staphylococcus aureus ATCC 6538 and on bacteria obtained from saliva samples of ten individuals. Mouthrinses containing chlorhexidine gluconate at $0.12 \%$, chlorhexidine gluconate at 0,2\%, chloride of cetilpyridine with and without fluorine, thymol, tricosane with fluorine, mallow extract with fluorine and xylital and hydrogen peroxide have been analysed. Diffusion in agar, method of the plate with orifice and with incubation at $37^{\circ} \mathrm{C}$ in aerobiosis and microaerophilia, was the technique utilized. After incubation, the presence or absence of the halo of growth inhibition around the orifices was observed. The halo formation showed antimicrobial activity. In the mouthrinses containing thymol, and fluorine associated with xylitol, no activity on the used bacteria was evidenced. The other mouthrinses presented efficacy on the bacteria, with the exception of those containing chloride of cetilpyridine that did not present activity on Pseudomona aeruginosa, and of the mouthrinse with mallow associated with fluorine and xylitol, without activity on P. aeruginosa, S. mutans and saliva bacteria. The mouthrinses containing triclosane with fluorine, hydrogen peroxide and chlorhexidine were the most effective, in accordance with the diameter of the formed inhibition halos and the used methodology. The obtained results proved that antiseptic substances may become a complementary option of controlling the dental biofilm and the buccal infections, in addition to the methods already recommended and of proven effect.
\end{abstract}

Keywords: Buccal antiseptics-Antimicrobial activity - Dental biofilm - Diffusion in agar.

\section{REFERÊNCIAS}

ADDY, M. O uso de anti-sépticos na terapia periodontal. In: LINDHE, J. Tratado de periodontia. 4.ed. Rio de Janeiro: Guanabara Koogan, 2005. p.450-477.
AGÊNCIA NACIONAL DE VIGILÂNCIA SANITÁRIA (Brasil). Resolução RDC n ${ }^{\circ}$. 211, de 14 de julho de 2005. Ficam estabelecidas a Definição e a Classificação de Produtos de Higiene Pessoal, Cosméticos e Perfumes, conforme Anexos I e II desta Resolução. 
Diário Oficial [da] República Federativa do Brasil, Poder Executivo, Brasília, DF, 18 jul. 2005.

BOTELHO, M.G. Fractional innibitory concentration index of combinations of antibacterial agents against cariogenic organisms. J. Dent., Kidlington, v.28, p.565-570, 2000.

BUGNO, A.N. et al. Enxaguatórios bucais: avaliação da eficácia antimicrobiana de produtos comercialmente disponíveis. R. Inst. Adolfo Lutz, São Paulo, v.65, n.1, p.40-45, 2006.

GEBRAN, M.P; GEBERT, A.P.O. Controle químico e mecânico de placa bacteriana. Tuiuti: Ciência e Cultura, Curitiba, n.26, v.3, p.4558, 2002.

GRANJEIRO, J.M. et al. O cloreto de cetilpiridínio e a placa bacteriana: uma revisão. R. Assoc. Paul. Cir. Dent., São Paulo, v.46, n.5, p857-860, 1993.

INSTITUTO NACIONAL DE CONTROLE DE QUALIDADE EM SAÚdE (Brasil). Procedimento operacional no. 65.3210.006. Rio de Janeiro, 2006.

LORENZO, J.L. Placa (biofilme) dental. In: Microbiologia para o estudante de Odontologia. São Paulo: Atheneu, 2004. p.7385.

MENDES, M.M.S.G. et. al. Agentes químicos para o controle da placa bacteriana. Periodontia, Fortaleza, v.5, n.2, p.253-256, 1995.
MONFRIN, R.C.P.; RIBEIRO, M.C. Avaliação in vitro de anti-sépticos bucais sobre a microbiota da saliva. R. Assoc. Paul. Cir. Dent., São Paulo, v.54, n.1, p.401-407, 2000.

MOTA, M.V.A. et al. Estudo comparativo in vivo da eficácia de dois enxaguatórios bucais sobre a formação da placa bacteriana supragengival: plano piloto. R. Odontol. UNICID, São Paulo, v.16, n.3, p.247-254, 2004.

PITTEN, F.A.; KRAMER, A. Efficacy of cetylpyridinium cloridre used as oropharyngeal antiseptic. Arzneimittelforschung, Aulendorf, v.51, n.7, p.588-595, 2001.

SABA-CHUJFI, E. et al. A eficácia da formulação contendo o anti-séptico triclosan associado ao copolímero gantrez e ao flúor, utilizada através de bochecho para controle químico da placa bacteriana. R. Assoc. Bras. Odontol., São Paulo, v.6, n.3, p.164-170, 1998.

SOUZA, R.R.; ABREU, M.H.N.G. Análise crítica da indicação da clorexidina no controle da placa bacteriana e doença periodontal. Arq. Odontol., Belo Horizonte, v.39, n.3, p.163254, 2003.

TIRAPELI, C.; ITO, I.Y. Avaliação do efeito de quatro anti-sépticos orais no nível de estreptococos mutans na saliva in vivo. R. Assoc. Bras. Odontol., São Paulo, v.11, n.1, p-47-51, 2003.

TORRES, C.R.G. et al. Agentes antimicrobianos e seu potencial de uso na Odontologia. PGR: Pós-Grad. R. Odontol., São José dos Campos, v.2, n.2, p.43-52, 2000 . 